\title{
Efeitos ambientais e genéticos sobre peso, perímetro escrotal e escores de avaliação visual à desmama em bovinos da raça Canchim ${ }^{1}$
}

\author{
Fabiana Barichello², Maurício Mello de Alencar ${ }^{3,5}$, Roberto Augusto de Almeida Torres \\ Júnior ${ }^{4}$, Luiz Otávio Campos da Silva ${ }^{4,5}$
}

\author{
1 Pesquisa financiada pela CAPES. \\ 2 Doutoranda em Genética e Melhoramento Animal, UNESP/Jaboticabal. \\ 3 Pesquisador da Embrapa Pecuária Sudeste. \\ ${ }^{4}$ Pesquisador da Embrapa Gado de Corte. \\ 5 Bolsista do CNPq.
}

RESUMO - Os efeitos de ano e época de nascimento, propriedade, sexo do bezerro, regime alimentar, idade do bezerro e idade da vaca ao parto, os efeitos aditivos direto e materno da raça Charolesa e o efeito de heterose materna entre as raças Charolesa e zebu foram avaliados pelo método dos quadrados míninos sobre características de importância econômica, como peso, perímetro escrotal e escores visuais de conformação frigorífica, de umbigo e de pelame à desmama em bovinos da raça Canchim. Utilizaram-se dados de 12.334 animais Canchim nascidos de 1999 a 2005. O ano e a época de nascimento, a propriedade, o regime alimentar e a idade da vaca ao parto (linear e quadrático) tiveram efeitos significativos sobre todas as características estudadas. Houve efeitos do sexo sobre o peso do bezerro à desmama e o escore de umbigo; da idade do bezerro sobre peso, perímetro escrotal e escores de conformação frigorífica e de pelame; e das proporções de Charolês no bezerro e na mãe sobre o peso, a conformação frigorífica e a qualidade de pelagem; e da heterozigose materna sobre peso, perímetro escrotal e escores de conformação frigorífica e de umbigo. Os efeitos aditivos diretos da raça Charolesa como desvio do zebu foram negativos sobre peso, conformação frigorífica e qualidade da pelagem à demama, enquanto os efeitos aditivos maternos foram positivos. Os efeitos heteróticos maternos foram positivos sobre peso, perímetro escrotal e escores de conformação frigorífica e de umbigo. Em geral, essas fontes de variação devem ser consideradas nas estimativas de parâmetros genéticos e nas avaliações genéticas dos animais Canchim para as características estudadas.

Palavras-chave: bovinos de corte, efeitos aditivos, efeitos de meio, efeitos heteróticos

\section{Environmental and genetic effects on weight, scrotal circumference and visual scores at weaning on Canchim beef cattle}

\begin{abstract}
The effects of calving year and season, property, sex of the calf, feeding regime, age of calf and age of dam at calving, maternal and direct additive effects of Charolais breed, and maternal heterosis effects among Charolais and zebu breeds were evaluated by the method of least squares on economical importance traits such as weight, scrotal circumference and visual scores for slaughter conformation, navel score and hair coat at weaning of the Canchim breed. Data from 12,334 Canchim calves born from 1999 to 2005 were used. Calving year and season, property, feeding regime and age of dam (linear and quadratic) had significant effects on all the studied characteristics. There were effects of sex on weaning weight and navel score; of age of the calf on weight, scrotal circumference and slaughter conformation and hair coat scores; and of proportion of Charolais on the calf and on the dam on weaning weight, and on scores of slaughter conformation and hair coat; and of maternal heterozygose on weight, scrotal circumference, slaughter conformation and navel scores. Additive direct effects of the Charolais as deviation of zebu were negative on weight, slaughter conformation and hair coat score at weaning, while the maternal additive effects were positive. Maternal heterotic effects were positive on weight, scrotal circumference, slaughter conformation and navel scores. In general, these sources of variation have to be taken into account on estimates of genetic parameters and on genetic evaluations of Canchim animals for the studied characteristics.
\end{abstract}

Key Words: additive effect, beef cattle, environmental effects, heterotic effects

Recebido em 5/5/2009 e aprovado em 5/3/2010.

Correspondências devem ser enviadas para: fabiana_barichello@yahoo.com.br 


\section{Introdução}

No Brasil, a viabilidade da atividade pecuária de corte depende, entre outros fatores, do potencial de produção dos animais e da capacidade de adaptação ao ambiente. Várias características são consideradas nos programas de avaliação genética de bovinos de corte no País, entre elas, o peso e o perímetro escrotal à desmama, que são ligadas, respectivamente, à produção e à eficiência reprodutiva, fáceis de mensurar em idades mais precoces e que possuem herdabilidade de magnitude média (Alencar, 2002). Entretanto, algumas características são difíceis de serem medidas, principalmente aquelas ligadas à produtividade e à adaptação, portanto, às vezes, não são contempladas nos programas de avaliação genética. Assim, têm-se utilizado escores visuais em alguns programas de melhoramento na tentativa de selecionar animais mais adaptados às condições de criação e, portanto, mais sustentáveis.

Alguns dos escores visuais de características produtivas mais utilizados na atualidade são os de conformação, precocidade e musculosidade (Cardoso et al., 2001; Jorge Júnior et al., 2001, 2004; Dal-Farra et al., 2002; Kippert et al., 2006). Entretanto, outra forma de avaliação dos animais com objetivo semelhante é a conformação frigorífica, que utiliza apenas um escore para predizer o potencial produtivo do animal como um todo (Silva, L., 2000).

No caso de reprodutores, o tamanho e o posicionamento do umbigo são características importantes, pois umbigos mais pronunciados ou pendulosos apresentam maior predisposição a lesões e traumatismos, podendo levar à perda do reprodutor (Lagos \& Fitzhugh, 1970). No Brasil, autores como Viu et al. (2002) utilizaram escores para avaliar o tamanho do umbigo.

Várias características do pelame são desejáveis para bovinos que vivem em regiões de clima tropical, como pelos curtos e assentados, alta densidade numérica, maior diâmetro dos pelos e pelame claro, que permitem maior proteção contra a radiação solar e o estresse térmico e, consequentemente, favorecem o desempenho zootécnico a campo (Silva, R., 2000). Apesar de sua importância, essas características são pouco utilizadas nos programas de avaliação genética, pois são de difícil avaliação objetiva. Entretanto, a avaliação dos animais por meio de escores de qualidade do pelame pode ser uma forma de classificar animais mais adaptados ao ambiente tropical (Silva, L., 2000).

No entanto, a seleção de animais com base em valores fenotípicos de características sem o ajuste para fatores ambientais e genéticos que as influenciam pode comprometer o progresso genético. Vários trabalhos da literatura trazem relatos sobre a influência de fatores ambientais e heteróticos (Alencar et al., 1993; Mascioli et al., 1996; Trematore et al., 1998; Perotto et al., 2000; Dal-Farra et al., 2002; Jorge Júnior et al., 2004) sobre escores visuais de conformação, precocidade e musculosidade e, ou, características de crescimento e de perímetro escrotal, mas há carência de estudos sobre os escores de conformação frigorífica, de qualidade do pelame e de umbigo.

Os objetivos neste estudo foram identificar possíveis fontes ambientais de variação e determinar os efeitos aditivos direto e materno da raça Charolesa em relação à zebu e da heterozigose materna entre a raça Charolesa e a zebu sobre o peso, o perímetro escrotal e os escores visuais de conformação frigorífica, de umbigo e de qualidade da pelagem à desmama em bovinos da raça Canchim pertencentes ao programa de melhoramento genético da raça Canchim.

\section{Material e Métodos}

Os dados utilizados neste trabalho foram provenientes de bovinos Canchim participantes da avaliação genética da Associação Brasileira de Criadores de Canchim feita em parceria com o Programa Embrapa de Melhoramento de Gado de Corte - Geneplus. Utilizaram-se dados de peso, perímetro escrotal e escores visuais à desmama de 12.344 animais nascidos no período de 1999 a 2005 (Tabela 1).

Para atribuição do escore de conformação frigorífica, que considera a estrutura da carcaça, o desenvolvimento da musculatura e a deposição de gordura subcutânea, inicialmente, foi feita inspeção geral dentro do lote procurando visualizar os animais que representassem os grupos superior, inferior e intermediário e, então, foram dados os escores individuais em relação ao grupo de contemporâneos. Os escores relativos de conformação frigorífica variaram de 1 a 6 , de modo que o escore 6 representa a expressão mais desejável da característica (Silva, L., 2000). Caso exista algum efeito de classificador, esse efeito encontra-se automaticamente incluído no grupo de contemporâneos.

O escore de umbigo foi atribuído a cada animal com base num padrão absoluto, que variou de 1 a 6 , de modo que 1 correspondeu a animais de umbigo maiores, mais pendulosos e de angulação superior a $45^{\circ}$ em relação ao ventre e 6 representou os animais com umbigo curto e colado ao ventre (Silva, L., 2000). A característica foi considerada como a mesma para machos e fêmeas e denominada apenas escore de umbigo. Para as análises estatísticas, o escore 1 passou a ser atribuído aos 
Tabela 1 - Características de importância econômica avaliadas à demama em bovinos da raça Canchim

\begin{tabular}{|c|c|c|c|c|c|c|}
\hline Característica & $\begin{array}{c}\text { № de } \\
\text { observações }\end{array}$ & Média & Mínimo & Máximo & Desvio-padrão & $\begin{array}{c}\text { Coeficiente } \\
\text { de variação (\%) }\end{array}$ \\
\hline Peso (kg) & 11.563 & 208,77 & 80,64 & 399,00 & 40,02 & 19,08 \\
\hline Perímetro escrotal (cm) & 5.020 & 18,78 & 11,00 & 30,00 & 2,40 & 12,80 \\
\hline Conformação frigorífica (escore) & 7.846 & 4,43 & 1 & 6 & 1,19 & 26,84 \\
\hline Umbigo (escore) & 8.598 & 1,99 & 1 & 6 & 1,07 & 21,33 \\
\hline Qualidade do pelame (escore) & 7.476 & 4,39 & 1 & 6 & 1,33 & 30,44 \\
\hline Idade do bezerro à desmama (dias) & 12.334 & 230,06 & 165 & 285 & 21,79 & 9,09 \\
\hline Idade da vaca ao parto (dias) & 12.334 & $2.225,00$ & 730 & 7.910 & $1.046,18$ & 46,22 \\
\hline Proporção de Charolês no animal & 12.334 & 0,6223 & 0,5625 & 0,6563 & 0,0179 & 2,88 \\
\hline Proporção de Charolês na mãe & 12.334 & 0,6216 & 0,5313 & 0,6563 & 0,0262 & 4,25 \\
\hline Proporção de heterozigose no animal & 12.334 & 0,4698 & 0,4512 & 0,4927 & 0,0090 & 1,90 \\
\hline Proporção de heterozigose materna & 12.334 & 0,5185 & 0,4512 & 0,7500 & 0,0891 & 17,65 \\
\hline
\end{tabular}

animais de umbigos menores e o escore 6 aos de umbigos maiores.

A nota de pelame também foi avaliada com referência a um padrão absoluto. A característica teve notas variando de 1 a 6 , de modo que o escore 1 representou aqueles animais com pelos compridos, sem brilho e com baixa densidade, não-desejáveis, enquanto o escore 6 referia-se aos animais com pelame considerado adaptado ao clima, ou seja, pelos lisos, brilhantes e em alta densidade (Silva, L., 2000).

O peso à desmama foi padronizado para 225 dias de idade, média de idade à desmama dos bezerros, utilizando-se o ganho de peso médio diário do nascimento à desmama.

A heterozigose do animal foi calculada de acordo com a seguinte fórmula: $\mathrm{H}=\sum \mathrm{P}_{\mathrm{i}}\left(1-\mathrm{V}_{\mathrm{i}}\right)$, em que $\mathrm{Pi}=$ fração da raça i (Charolesa e zebu) no pai; e $\mathrm{Vi}$ = fração da raça i (Charolesa e zebu) na mãe. Para a heterozigose materna, $\mathrm{Pi}$ = fração da raça i (Charolesa e zebu) no avô materno; e $\mathrm{Vi}$ = fração da raça i (Charolesa e zebu) na avó materna. A proporção de Charolês no animal foi calculada como a média das proporções de Charolês no pai e na mãe do animal (Tabela 2).

Os dados de peso, perímetro escrotal e escores visuais foram analisados pelo método dos quadrados mínimos utilizando-se modelos estatísticos que incluíram os efeitos de ano e época de nascimento (1 - dezembro a fevereiro;
2 - março a maio; 3 - junho a agosto; e 4 - setembro a novembro), propriedade, regime alimentar (1 - pasto; 2 - pasto adubado; 3 - suplementação; e 4 - confinamento ou exposição), sexo do bezerro e as covariáveis proporção de Charolês no animal, proporção de Charolês na mãe, heterozigose materna e idade do bezerro (efeito linear) e idade da vaca ao parto (efeitos linear e quadrático), além do resíduo. A proporção de heterozigose no animal não foi considerada nas análises por ter apresentado pequena variação, com valores mínimo e máximo de 0,4512 e 0,4927, respectivamente, e coeficiente de variação de 1,90\%.

\section{Resultados e Discussão}

Os efeitos de ano e época de nascimento, regime alimentar, propriedade e idade da vaca ao parto influenciaram $(\mathrm{P}<0,01)$ todas as características estudadas (Tabela 3$)$. O sexo do bezerro influenciou $(\mathrm{P}<0,01)$ o peso e o escore de umbigo, e a idade do bezerro influenciou $(\mathrm{P}<0,01)$ o peso, $\mathrm{o}$ perímetro escrotal e os escores de conformação frigorífica e de qualidade da pelagem, visto que o peso foi apenas padronizado, o que não retiraria o efeito da idade.

Os efeitos de ano de nascimento e de propriedade sobre as características peso, perímetro escrotal e os escores de conformação frigorífica, de umbigo e de qualidade da

Tabela 2 - Grupos genéticos do pai e da mãe nos acasalamentos, número de animais com dados do acasalamento, proporções de Charolês materna e no animal e proporção de heterozigose materna

\begin{tabular}{|c|c|c|c|c|c|c|c|c|}
\hline \multirow[b]{2}{*}{$\begin{array}{c}\text { Grupo genético } \\
\text { do } \text { pai }^{1}\end{array}$} & \multirow[b]{2}{*}{$\begin{array}{c}\text { Grupo genético } \\
\text { da mãe }\end{array}$} & \multirow[b]{2}{*}{$\begin{array}{l}\text { № animais do } \\
\text { acasalamento }\end{array}$} & \multicolumn{2}{|c|}{$\begin{array}{c}\text { Proporção de } \\
\text { Charolês no animal }\end{array}$} & \multicolumn{2}{|c|}{$\begin{array}{l}\text { Proporção de } \\
\text { heterozigose materna }\end{array}$} & \multicolumn{2}{|c|}{$\begin{array}{l}\text { Proporção de } \\
\text { Charolês materna }\end{array}$} \\
\hline & & & Mínima & Máxima & Mínima & Máxima & Mínima & Máxima \\
\hline $\mathrm{CN}$ & V & 708 & 0,5625 & 0,6094 & 0,5000 & 0,5087 & 0,5313 & 0,5781 \\
\hline $5 / 8$ & $5 / 8$ & 146 & 0,6250 & 0,6250 & 0,7500 & 0,7500 & 0,6250 & 0,6250 \\
\hline $\mathrm{CN}$ & $5 / 8 \mathrm{Ch}$ & 100 & 0,6055 & 0,6406 & 0,7500 & 0,7500 & 0,6250 & 0,6250 \\
\hline $\mathrm{CN}$ & $\mathrm{CN}$ & 9.137 & 0,5723 & 0,6563 & 0,4512 & 0,4941 & 0,5586 & 0,6563 \\
\hline $\mathrm{CN}$ & MA & 1.537 & 0,6133 & 0,6563 & 0,6875 & 0,7070 & 0,6465 & 0,6563 \\
\hline MA & MA & 706 & 0,6514 & 0,6523 & 0,6875 & 0,7070 & 0,6465 & 0,6563 \\
\hline
\end{tabular}

${ }^{1} \mathrm{CN}=$ Canchim; $\mathrm{V}=$ 35/64 Charolês + 29/64 zebu; 5/8 = 5/8Charolês + 3/8 zebu; MA = 21/32 Charolês + 11/32 zebu. 
Tabela 3 - Resumo das análises de variância do peso, do perímetro escrotal e dos escores visuais de conformação frigorífica, de umbigo e de qualidade da pelagem

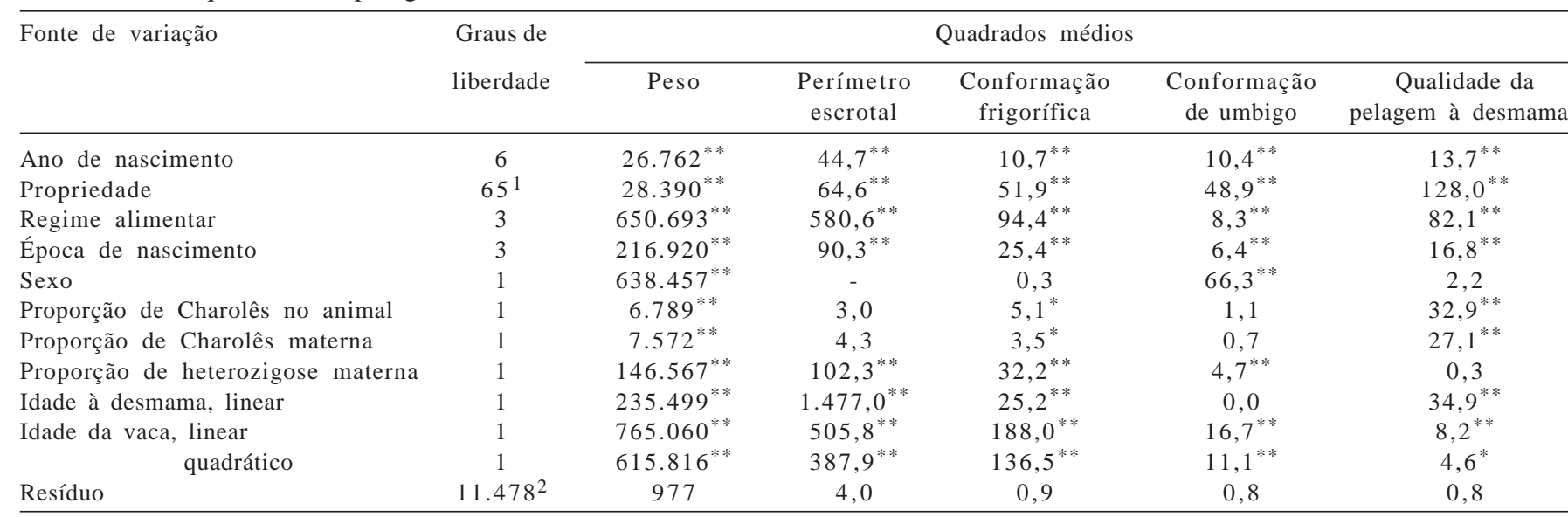

${ }^{* *} \mathrm{P}<0,01 ;{ }^{*} \mathrm{P}<0,05$.

${ }^{1}$ Graus de liberdade $=54,46,50$ e 47 para perímetro escrotal, conformação frigorífica, conformação de umbigo e qualidade da pelagem à desmama, respectivamente.

2 Graus de liberdade $=4.947,7.780,8.528$ e 7.409 para perímetro escrotal, conformação frigorífica, conformação de umbigo e qualidade da pelagem à demama, respectivamente.

pelagem são, provavelmente, consequência de diferenças na incidência do clima, na disponibilidade de alimentos e no manejo e potencial genético dos animais entre os anos e as propriedades.

Efeitos de ano de nascimento foram observados também por outros autores (Martins et al., 2000; Sarmento et al., 2003). Os efeitos de ano de nascimento sobre conformação frigorífica não eram esperados, uma vez que os escores de conformação frigorífica foram atribuídos em relação ao grupo de contemporâneos, o que pode configurar problemas na atribuição dos escores. Entretanto, outros autores (Cardoso et al., 2001; Jorge Júnior et al., 2001) verificaram efeitos de data juliana de nascimento sobre as características conformação, precocidade e musculosidade, que também são escores relativos.

Os bezerros nascidos de junho a agosto foram mais pesados e apresentaram maior perímetro escrotal e melhor conformação frigorífica (Tabela 4). A ausência de problemas sanitários durante as primeiras semanas de vida e a desmama em época mais favorável, com maior disponibilidade de forragem, provavelmente foram responsáveis pelo melhor desempenho dos bezerros nascidos no período seco do ano. Alencar \& Barbosa (1982), Alencar et al. (1993) e Mascioli et al. (1996) também verificaram a importância desses efeitos sobre peso e perímetro escrotal na raça Canchim. Nesse caso, também não eram esperados efeitos de época de nascimento sobre conformação frigorífica, uma vez que os escores eram relativos. Entretanto, outros autores também verificaram efeitos de época de nascimento sobre escores relativos (Cardoso et al., 2001).

Os machos foram mais pesados que as fêmeas (Tabela 4), fato que está de acordo com a literatura
(Alencar \& Barbosa, 1982; Mascioli et al., 1996; Guimarães et al., 2003; Bocchi et al., 2004). A ausência de efeito de sexo sobre o escore de conformação frigorífica à desmama diverge dos resultados obtidos em outros trabalhos, mas pode ser atribuída ao fato de que as avaliações eram relativas aos lotes, que consideraram o sexo na sua formação. Cardoso et al. (2001) estudaram outros escores visuais (conformação, precocidade, musculatura e tamanho), também relativos aos grupos de contemporâneos, e relataram a presença do efeito de sexo sobre eles.

Não houve diferenças entre os sexos para o escore de pelame, mas, para o escore de umbigo, os valores obtidos para os machos foram maiores que para as fêmeas (Tabela 4). É possível que a presença de prepúcio nos machos torne o conjunto umbigo-prepúcio mais pesado levando o avaliador a dar notas piores (ou maiores) para os machos. Viu et al. (2002) também relataram maiores escores de umbigo para machos.

O efeito de época de nascimento sobre o escore de pelame neste trabalho pode ser reflexo do efeito de época sobre o desempenho ponderal dos bezerros, ou seja, bezerros mais desenvolvidos e de melhor conformação, em razão da melhor época de nascimento, apresentaram pelos mais lisos e assentados (Tabela 4). Essa explicação, entretanto, não pode ser dada para o efeito de época sobre o escore de umbigo.

Os bezerros em confinamento (exposição) e aqueles sob suplementação foram os mais pesados e com maior perímetro escrotal (Tabela 4). O efeito de regime alimentar sobre a característica qualidade da pelagem à desmama pode ser reflexo dos efeitos sobre as características de crescimento, fato que não explica o efeito sobre o escore de 
Tabela 4 - Médias estimadas de características de importância econômica à desmama de acordo com a época de nascimento, o sexo do bezerro e o regime alimentar

\begin{tabular}{|c|c|c|c|c|c|}
\hline & Peso & $\begin{array}{l}\text { Perímetro } \\
\text { escrotal }\end{array}$ & $\begin{array}{l}\text { Conformação } \\
\text { frigorífica }\end{array}$ & $\begin{array}{l}\text { Conformação } \\
\text { de umbigo }\end{array}$ & $\begin{array}{c}\text { Qualidade de } \\
\text { pelagem à desmama }\end{array}$ \\
\hline \multicolumn{6}{|l|}{ Época } \\
\hline Dezembro - fevereiro & $214 \pm 1,35$ & $19,16 \pm 0,13$ & $4,17 \pm 0,05$ & $2,35 \pm 0,04$ & $3,87 \pm 0,05$ \\
\hline Junho - agosto & $237 \pm 1,32$ & $19,92 \pm 0,13$ & $4,48 \pm 0,05$ & $2,44 \pm 0,04$ & $4,07 \pm 0,05$ \\
\hline Setembro - novembro & $230 \pm 1,27$ & $19,63 \pm 0,13$ & $4,28 \pm 0,05$ & $2,35 \pm 0,04$ & $3,86 \pm 0,05$ \\
\hline Fêmea & $217 \pm 1,25$ & - & $4,30 \pm 0,05$ & $2,31 \pm 0,04$ & $3,93 \pm 0,05$ \\
\hline \multicolumn{6}{|l|}{ Regime alimentar } \\
\hline Pasto & $202 \pm 0,99$ & $18,88 \pm 0,10$ & $4,10 \pm 0,04$ & $2,39 \pm 0,03$ & $3,59 \pm 0,03$ \\
\hline Pasto adubado & $214 \pm 2,83$ & $18,36 \pm 0,29$ & $3,78 \pm 0,14$ & $2,64 \pm 0,10$ & $3,89 \pm 0,16$ \\
\hline Suplementação & $222 \pm 1,91$ & $19,52 \pm 0,19$ & $4,39 \pm 0,08$ & $2,40 \pm 0,07$ & $3,96 \pm 0,07$ \\
\hline Confinamento - Exposição & $261 \pm 1,62$ & $21,72 \pm 0,16$ & $4,91 \pm 0,06$ & $2,18 \pm 0,05$ & $4,33 \pm 0,05$ \\
\hline
\end{tabular}

umbigo. Entretanto, é possível que o tamanho do umbigo tenha sido um dos critérios utilizados na escolha dos animais a serem confinados, o que explicaria a menor média de tamanho de umbigo para esse grupo.

O efeito da idade da vaca ao parto teve comportamento quadrático sobre todas as características estudadas. Para peso, perímetro escrotal, conformação frigorífica e qualidade da pelagem à desmama, o bezerro teve desempenho crescente com o aumento da idade da vaca, até a vaca atingir a maturidade fisiológica, com pico por volta dos 8 anos de idade (3.000 dias), decrescendo gradativamente com seu envelhecimento. Resultados semelhantes foram relatados por outros autores que trabalharam com o peso à desmama (Alencar et al., 1982; Mascioli et al., 1996; Pelicioni et al., 2002; Guimarães et al., 2003). As vacas, por volta dos 5.500 dias de idade (15 anos), começaram a desmamar bezerros mais leves em comparação às vacas primíparas, tendência também observada por Pelicioni et al. (2002) em vacas da raça Gir aos 12 anos, e por Bocchi (2004), em vacas Nelore aos 15 anos. Esses resultados comprovam que não é interessante a manutenção de vacas no rebanho depois de determinada idade.

Não foi encontrado relato na literatura sobre a influência da idade da vaca ao parto no escore de conformação frigorífica à desmama, no entanto, existem alguns trabalhos com escores visuais de conformação, precocidade e musculosidade (Cardoso et al., 2001; Jorge Júnior et al., 2001; Dal-Farra et al., 2002; Jorge Júnior et al., 2004; Kippert et al., 2006) em diferentes raças bovinas e que apresentaram comportamento semelhante ao encontrado nesta pesquisa para conformação frigorífica. Também não foram encontrados na literatura relatos sobre os efeitos da idade da vaca ao parto na qualidade da pelagem à demama.
O escore de umbigo do bezerro foi menor no início e no final da vida produtiva da vaca, ou seja, os maiores escores ocorreram quando a vaca se encontrou em idade mediana, quando atinge a maturidade fisiológica. Os efeitos de idade da vaca sobre os escores de qualidade da pelagem e de umbigo à desmama são menos pronunciados que sobre as características de produção (peso à demasma, perímetro escrotal e conformação frigorífica). É possível que os efeitos de idade da vaca sobre os escores de qualidade da pelagem e de umbigo à desmama sejam reflexo de seus efeitos sobre o peso à desmama e sobre a conformação, ou seja, os bezerros mais pesados e de melhor conformação frigorífica possuíam pelame mais assentado e curto e umbigo aparentemente mais curto.

O efeito da idade da vaca ao parto sobre todas as características é coerente, pois as características peso, perímetro escrotal e conformação frigorífica aumentam de acordo com a idade da vaca: chegam a um valor máximo e depois decrescem com seu envelhecimento. O efeito linear da idade do bezerro à desmama foi negativo sobre peso $(b=-0,2456)$ e positivo para perímetro escrotal $(b=0,0311)$, conformação frigorífica $(b=0,0033)$ e qualidade da pelagem à demama $(b=0,0039)$. O efeito linear negativo da idade do bezerro sobre peso justifica-se pela padronização que a característica recebeu usando-se o ganho de peso médio diário do nascimento à desmama, assumido constante, em que os bezerros desmamados mais novos foram favorecidos em relação aos desmamados mais velhos. Mascioli (1995), ao padronizar o peso à desmama para 240 dias de idade de bezerros Canchim, também encontrou coeficiente de regressão negativo da idade do bezerro à desmama. Todas as demais características tornaram-se mais expressivas com o aumento da idade, ou seja, animais mais velhos apresentaram maiores escores 
de conformação frigorífica e de pelame, além de maior perímetro escrotal.

Corrêa et al. (2006) também encontraram efeito significativo apenas linear da idade sobre o peso à desmama de bovinos Devon, no entanto, como não fizeram préajuste dos dados, esse efeito foi positivo. Ortiz Peña et al. (2000), em pesquisa com características ao sobreano, relataram a influência linear positiva da idade sobre o perímetro escrotal. Dal-Farra et al. (1999) relataram efeito linear e quadrático da idade sobre o perímetro escrotal ao sobreano, e isso indica que o perímetro escrotal apresenta desenvolvimento semelhante ao de peso.

O comportamento do escore de conformação frigorífica se assemelha ao de outros escores visuais (conformação, precocidade, musculosidade e tamanho), segundo Jorge Júnior et al. (2001 e 2004), Kippert et al. (2006) e Cardoso et al. (2001) em estudos com animais das raças Nelore, Charolês e Angus, respectivamente. Nessas pesquisas, os escores visuais maiores foram atribuídos aos indivíduos desmamados mais velhos e os menores, aos desmamados mais cedo, ou seja, animais mais velhos tenderam a ser maiores e mais pesados, levando ao confundimento do avaliador, que emitiu melhores escores para esses animais.

O efeito aditivo direto da raça Charolesa como desvio da zebu, estimado pelo coeficiente de regressão da variável dependente sobre a proporção de Charolês no animal, foi negativo e significativo apenas para peso $(b=-90,7477)$, conformação frigorífica ( $b=-3,0733)$ e qualidade da pelagem à desmama $(b=-8,1132)$. Esses resultados indicam que bezerros com maior proporção de genes da raça Charolesa apresentaram piores desempenhos na fase de cria, independentemente dos outros fatores.

Esse resultado era esperado para o escore de qualidade de pelame, visto que a raça Charolesa apresenta pelos maiores e mais grossos, diferentemente de animais de raças zebuínas, em que o pelame característico é justamente aquele mais liso, curto e assentado, um dos fatores que contribuem para os animais de raças zebuínas serem mais adaptados ao clima tropical.

O efeito aditivo direto negativo sobre o peso à desmama do bezerro difere dos relatos de Dillard et al. (1980), Peacock et al. (1981) e Trematore et al. (1998) de que, quanto maior a proporção de genes da raça Charolesa como desvio das raças Hereford, Brahman e Nelore, respectivamente, maior o desenvolvimento do bezerro. Trematore et al. (1998) atribuíram esse comportamento às características inerentes à raça Charolesa, que é de grande porte e tem elevado potencial para crescimento em comparação à Nelore.
Teixeira et al. (2005) estudaram bezerros mestiços Nelore $\times$ Hereford e Nelore $\times$ Angus e encontraram efeito aditivo direto para a raça Nelore superior ao da raça Hereford e inferior ao da raça Angus, o que levou os autores a creditarem esse efeito à utilização de touros Nelore de qualidade superior aos Hereford.

Uma explicação para o efeito aditivo direto negativo do Charolês em relação ao zebu talvez seja o fato de os touros do grupo genético 21/32 Charolês + 11/32 zebu, responsáveis pelas proporções mais elevadas de Charolês nos bezerros (Tabela 2), terem, provavelmente, sofrido menor pressão de seleção em comparação aos do grupo Canchim, resultando em filhos de mais baixo desempenho.

As menores notas de conformação frigorífica com o aumento da proporção de Charolês no bezerro podem ser consequência do efeito semelhante sobre o peso à desmama. O efeito aditivo materno da raça Charolesa como desvio do zebu, estimado pelo coeficiente de regressão da variável dependente sobre a proporção de Charolês materna, foi significativo e positivo para as características peso ( $b=61,8939$ ), conformação frigorífica ( $b=1,6208$ ) e qualidade da pelagem à demama $(b=4,6433)$. Esses resultados indicam que, quanto maior a proporção de genes da raça Charolesa na mãe, maior o peso e melhores os escores de conformação frigorífica e qualidade da pelagem à desmama do bezerro. Esse efeito positivo da proporção de genes da raça Charolesa na vaca pode ser resultado do maior potencial leiteiro da raça Charolesa em relação à zebuína. Esses resultados diferiram dos encontrados por Trematore et al. (1998) e Teixeira et al. (2005), que relataram efeitos aditivos maternos negativos das raças Charolesa, Hereford e Angus, como desvio da raça Nelore, respectivamente, para o peso à desmama.

A pequena amplitude dos valores de proporção de Charolês no animal $(0,5527$ a 0,6563$)$ e de proporção de Charolês materna $(0,5313$ a 0,6563$)$ nos animais deste estudo impediu interpretação mais profunda dos resultados, pois extrapolar esses valores para animais puros não seria correto, isto é, se houvesse valores variando entre os extremos ( 0 a 1), animais puros e vários níveis de cruzamento, o comportamento das características em função das frações de genes das raças poderia não ser o mesmo.

A heterozigose materna foi significativa e positiva para peso ( $b=50,9682)$, perímetro escrotal $(b=2,0562)$, conformação frigorífica $(b=0,8929)$ e umbigo $(b=0,7520)$. Assim, quanto maior a porcentagem de heterozigose materna, maiores serão o peso, o perímetro escrotal e os escores de conformação frigorífica e de umbigo. 
Dillard et al.(1980), em pesquisa com cruzamentos entre animais Charolês, Angus e Hereford; Peacock et al. (1981), em animais de cruzamentos Charolês e Brahman; e Trematore et al. (1998), em cruzamentos de animais Charolês $\times$ Nelore, também obtiveram efeito positivo da heterozigose materna sobre o peso à desmama. Gregory \& Cundiff (1980) relataram que $60 \%$ ou mais da heterose em características que contribuem para o peso ao desmame é atribuída à heterose materna e relataram aumento de $23 \%$ na quantidade de quilos de bezerros desmamados por vaca colocada em reprodução, em razão dos efeitos heteróticos na fertilidade, na produção de leite, na sobrevivência e no desenvolvimento do bezerro. Koch et al. (1989) também relataram aumento de $23 \%$ na produção por vaca em cruzamentos Bos taurus $\times$ Bos taurus em áreas de clima temperado e de $50 \%$ em cruzamentos Bos indicus $\times$ Bos taurus em áreas de clima subtropical, como consequência do efeito de heterose. Dal-Farra et al. (2002) estimaram valores de heterose de $8,5 \%$ a $10,9 \%$, associados a heterozigose materna em animais mestiços Angus $\times$ Nelore e Hereford $\times$ Nelore para escores visuais de conformação, precocidade e musculosidade.

\section{Conclusões}

Efeitos de ambiente, como ano e época de nascimento, proprietário, sexo do bezerro e regime alimentar, devem ser considerados na estimação de componentes de variância e predição de valores genéticos para peso, perímetro escrotal e escores visuais de conformação frigorífica, de umbigo e de pelame à desmama na raça Canchim. Também devem ser consideradas nos modelos estatísticos as covariáveis porcentagem de Charolês no bezerro e na mãe para o peso e os escores de conformação frigorífica e de pelagem e de heterozigose materna para o peso e os escores de conformação frigorífica, de pelagem e de umbigo.

\section{Referências}

ALENCAR, M.M. Critérios de seleção e a moderna pecuária bovina de corte brasileira. In: SIMPÓSIO BRASILEIRO DE MELHORAMENTO ANIMAL, 4., 2002, Campo Grande. Anais... Campo Grande: Sociedade Brasileira de Zootecnia, 2002. (CD-ROM).

ALENCAR, M.M.; BARBOSA, P.F. Fatores que influenciam os pesos de bezerros Canchim ao nascimento e à desmama. Pesquisa Agropecuária Brasileira, v.17, n.10, p.1535-1540, 1982.

ALENCAR, M.M.; BARBOSA, P.F.; BARBOSA, R.T. et al. Parâmetros genéticos para peso e circunferência escrotal em touros da raça Canchim. Revista da Sociedade Brasileira de Zootecnia, v.22, n.4, p.572-583, 1993.

BOCCHI, A.L.; TEIXEIRA, R.A.; ALBUQUERQUE, L.G. Idade da vaca e mês de nascimento sobre o peso ao desmame de bezerros
Nelore nas diferentes regiões brasileiras. Acta Scientiarum, v.26, n.4, p.475-482, 2004.

CARDOSO, F.F.; CARDELLINO, R.A.; CAMPOS, L.T. Fatores ambientais sobre escores de avaliação visual à desmama em bezerros Angus Criados no Rio Grande do Sul. Revista Brasileira de Zootecnia, v.30, n.2, p.318-325, 2001.

CORRÊA, M.B.B.; DIONELLO, N.J.L.; CARDOSO, F.F. Influência ambiental sobre características de desempenho pré-desmama de bovinos Devon no Rio Grande do Sul. Revista Brasileira de Zootecnia, v.35, n.3, p.1005-1011, 2006 (supl.).

DAL-FARRA, R.A.; ROSO, V.M.; KILPP, D.V. Fatores de correção do perímetro escrotal para efeitos de heterozigose individual, idade e peso em touros mestiços Angus x Nelore. In: REUNIÃO ANUAL DA SOCIEDADE BRASILEIRA DE ZOOTECNIA, 36., 1999, Porto Alegre. Anais... Porto Alegre: Sociedade Brasileira de Zootecnia/Gmosis, [1999]. (CD-ROM).

DAL-FARRA, R.A.; ROSO, V.M.; SCHENKEL, F.S. Efeitos de ambiente e de heterose sobre o ganho de peso do nascimento ao desmame e sobre os escores visuais ao desmame de bovinos de corte. Revista Brasileira de Zootecnia, v.31, n.3, p.1350-1361, 2002 (supl.).

DILLARD, E.U.; RODRIGUEZ, O.; ROBINSON, O.W. Estimation of additive and nonadditive direct and maternal genetic effects from crossbreeding beef cattle. Journal of Animal Science, v.50, n.4, p.653-663, 1980 .

GREGORY, K.E.; CUNDIFF, L.V. Crossbreeding in beef cattle: evaluation of systems. Journal of Animal Science, v.51, n.5, p.1224-1242, 1980

GUIMARÃES, L.B.; FERRAZ FILHO, P.B.; SOUZA, J.C. et al. Aspectos genéticos e de ambiente sobre pesos pré e pós desmama em bovinos da raça Tabapuã na região pecuária oeste São Paulo - Paraná. Archives of Veterinary Science, v.8, n.1, p.109-119, 2003.

JORGE JÚNIOR, J.; PITA, F.V.C.; FRIES, L.A. et al. Influência de alguns fatores de ambiente sobre os escores de conformação, precocidade e musculatura à desmama em um rebanho da raça Nelore. Revista Brasileira de Zootecnia, v.30, n.6, p.1697-1703, 2001.

JORGE JÚNIOR, J.; DIAS, L.T.; ALBUQUERQUE, L.G. Fatores de correção de escores visuais de conformação, precocidade $e$ musculatura, à desmama, para idade da vaca ao parto, data juliana de nascimento e idade à desmama em bovinos da raça Nelore. Revista Brasileira de Zootecnia, v.33, n.6, p.2044-2053, 2004 (supl. 2).

KIPPERT, C.J.; RORATO, P.R.N.; CAMPOS, L.T. et al. Efeito de fatores ambientais sobre escores de avaliação visual à desmama e estimativa de parâmetros genéticos, para bezerros da raça Charolês. Ciência Rural, v.36, n.2, p.579-585, 2006

KOCH, R.; CUNDIFF, L.V.; GREGORY, K.E. Beef cattle resource utilization. Brazilian Journal of Genetics, v.12, n.3, p.55-80, 1989.

LAGOS, F.; FITZHUGH JR., H.A. Factors influencing preputial prolapse in yearling bulls. Journal of Animal Science, v.30, p.949-952, 1970.

MARTINS, G.A.; MARTINS FILHO, R.; LIMA, F.A.M. et al Influência de fatores genéticos e de meio sobre o crescimento de bovinos da raça Nelore no estado do Maranhão. Revista Brasileira de Zootecnia, v.29, n.1, p.103-107, 2000.

MASCIOLI, A.S. Estimativas de parâmetros genéticos e proposição de critérios de seleção para pesos em bovinos da raça Canchim. 1995. 95f. Dissertação (Mestrado em Zootecnia) - Faculdade de Ciências Agrárias e Veterinárias/ Unesp, Jaboticabal.

MASCIOLI, A.S.; ALENCAR, M.M.; BARBOSA, P.F. et al. Influência de fatores de meio sobre pesos de animais da raça Canchim. Revista da Sociedade Brasileira de Zootecnia, v.25, n.5, p.853-865, 1996.

ORTIZ PEÑA, D.D.; QUEIROZ, S.A.; FRIES, L.A. Estimação de fatores de correção do perímetro escrotal para idade e peso 
corporal em touros jovens da raça Nelore. Revista Brasileira de Zootecnia, v.29, n.6, p.1667-1675, 2000.

PEACOCK, F.M.; KOGER, M.; OLSON, T.A. et al. Additive genetic and heterosis effects in crosses among cattle breeds of british, European and zebu origin. Journal of Animal Science, v.52, n.5, p.1007-1013, 1981.

PELICIONI, L.C.; PASCOA, L.; MUNIZ, C.A.S.D. et al. Efeito da idade da vaca ao parto e da data juliana de nascimento sobre características pré-desmama de bezerros da raça Gir. Revista Brasileira de Zootecnia, v.31, n.1, p.61-70, 2002.

PEROTTO, D.; CUBAS, A.C.; MOLETTA, J.L. et al. Heterose sobre os pesos de bovinos Canchim e Aberdeen Angus e de seus cruzamentos recíprocos. Pesquisa Agropecuária Brasileira, v.35, n.12, p.2511-2520, 2000

SARMENTO, J.L.R.; PIMENTA FILHO, E.C.; RIBEIRO, M.N. et al. Efeitos ambientais e genéticos sobre o ganho em peso diário de bovinos Nelore no estado da Paraíba. Revista Brasileira de Zootecnia, v.32, n.2, p.325-330, 2003.
SILVA, L.O.C. Programa de melhoramento genético da raça Canchim. In: CONVENÇÃO NACIONAL DA RAÇA CANCHIM, 4., 2000, São Carlos. Anais... São Carlos: Associação Brasileira de Criadores de Canchim, 2000. p.70-75.

SILVA, R.G. Introdução a bioclimatologia animal. São Paulo: Nobel, 2000. 286p.

TEIXEIRA, R.A.; ALBUQUERQUE, L.G. Heteroses materna e individual para ganho de peso pré-desmama em bovinos Nelore $x$ Hereford e Nelore x Angus. Arquivo Brasileiro de Medicina Veterinária e Zootecnia, v.57, n.4, p.518-523, 2005.

TREMATORE, R.L.; ALENCAR, M.M.; BARBOSA, P.F. et al. Estimativas de efeitos aditivos e heteróticos para características de crescimento pré-desmama em bovinos Charolês-Nelore. Revista Brasileira de Zootecnia, v.27, n.1, p.87-94, 1998.

VIU, M.; TONHATI, H.; CERÓN-MUNÕZ, M.F. et al. Parâmetros genéticos do peso e escores visuais de prepúcio e umbigo em gado de corte. Ars Veterinária, v.18, p.179-184, 2002. 